\title{
LA ARQUITECTURA INSTITUCIONAL POLÍTICA EN GALICIA DURANTE LA AUTARQUÍA
}

Miguel Abelleira Doldán

Data recepción: 2016/12/11

Universidade da Coruña

Data aceptación: 2018/02/16

Contacto autor: miguel.abelleira@udc.es

ORCID: https://orcid.org/0000-0001-5110-0595

\section{RESUMEN}

Tras la Guerra Civil española y el consiguiente cambio de régimen político, la arquitectura se convirtió en una herramienta transmisora de ideología y a la vez en un símbolo del poder. Esta relación se evidenció en las arquitecturas institucionales políticas. Las que se realizaron en Galicia no fueron una excepción a esa regla en ese momento indiscutida. A partir del estudio de una documentación inédita y desde una óptica disciplinar, se analizan dichas arquitecturas que poseen una carga semántica indudable y que se han convertido en referentes urbanos en sus respectivas ciudades, adecuándose a los nuevos usos democráticos sin perder su carácter institucional.

Palabras clave: historia de la arquitectura, política, arquitectura institucional, autarquía, Galicia

\section{ABSTRACT}

Following the Spanish Civil War and the subsequent regime change, architecture became both a tool for transmitting ideology and a symbol of power. This relationship manifested itself in political institutional architecture. The architecture created in Galicia was no exception to a rule that was, at the time, unquestioned. Analysis of it is based on the study of unpublished documentation and from a disciplinary point of view. It is an architecture that possesses an undeniable semantic charge and which has become an urban reference point in each respective city, adapting itself to new democratic usages without relinquishing its institutional character.

Keywords: history of architecture, politics, institutional architecture, autarchy, Galicia

\section{Introducción}

En España se han denominado los dos períodos consecutivos nucleados en torno al 1 de abril de 1939 como Guerra Civil y Franquismo, denominándose Autarquía a la primera etapa de éste, que en su dinámica histórica se entrecruza con la que en el resto del mundo supuso la Segunda Guerra Mundial y sus consecuencias inmediatas, con una clara repercusión en nuestro país. Puesto que este trabajo versa sobre la Autarquía precisamos definir sus límites temporales para así acotar el ámbito del estudio que se va a realizar. Fijamos el final de la Guerra Civil, que supuso el inicio de la dictadura franquista, como límite inferior y punto de arranque del período. Las firmas del Concordato con la Santa Sede el 27 de agosto de 1953 y de los acuerdos de cooperación con los Estados Unidos de índole defensiva, militar y económica el 26 de septiembre del mismo año fueron dos hitos importantes de carácter político que permitieron a España recuperar en parte la normalidad en su política exterior y cerrar definitivamente el aislamiento internacional que se había iniciado en 1946 con su rechazo a ser admitida en la recién 
creada O.N.U., favoreciéndose de este modo la reanudación de todo tipo de intercambios con el extranjero. Internamente ambos hechos fueron presentados como un momento de apogeo personal del dictador al mejorar su imagen fuera de España. Por ello tomamos 1953 como fecha final del ámbito temporal del estudio al optar por los hechos referidos que, aunque presentan una naturaleza no disciplinar, implicaron un cambio fundamental en la política española.

Las autoridades de la época entendieron la arquitectura como mecanismo transmisor de ideología y como símbolo del poder, tal y como se manifiesta en la arquitectura de promoción pública de ese tiempo, que conforma una realidad edificada cuya importancia sólo es equiparable en su diversidad y en su magnitud a la situación posterior a la entrada en vigor del Estado de las Autonomías, cuando éstas tuvieron que equipar sus territorios al asumir la titularidad de competencias que antes estaban centralizadas. Donde mejor se aprecia esta relación entre arquitectura y poder es en los edificios institucionales, entendiendo como tales aquéllos que albergan las sedes de instituciones y organismos de ámbito nacional, que fueron proyectados y construidos con el fin de exhibir la preeminencia del poder central sobre el provincial o el local. Por el uso al que están destinados, consecuencia directa del tipo de institución cliente que los encarga, podemos dividirlos en políticos, cuando están vinculados directamente al control ideológico propio del nuevo régimen, como gobiernos civiles y casas sindicales; administrativos, que son los que alojan los usos y actividades derivados de la nueva administración del Estado, como delegaciones ministeriales y sedes de jefaturas e institutos; y económicos, que albergan las actividades económicas de naturaleza diversa, como las sedes del Banco de España y de las compañías de comunicaciones Compañía Telefónica Nacional de España y Correos y Telégrafos.

Dada la naturaleza de este trabajo, limitaremos su objetivo a abordar el estudio de las arquitecturas institucionales políticas que se proyectaron o construyeron en Galicia durante la Autarquía, en concreto en sus siete ciudades', puesto que históricamente el poder político ha preferido el ámbito urbano para localizar sus sedes². Se realizará un análisis disciplinar apoyado en una base documental inédita, que intentará huir de las simplificaciones resultado de juicios de valor genéricos y apriorísticos. La fuerte caracterización ideológica de ese tiempo ha hecho que en numerosas ocasiones se haya juzgado la arquitectura de entonces desde parámetros políticos, lo que ha llevado a calificarla como un hecho acotado en sí mismo y reaccionario, tomando como punto de partida una interpretación maniquea elemental que le ha asignado un papel negativo en el estudio ordenado de la arquitectura del segundo tercio del siglo XX.

Para ello explicaremos en primer lugar cuáles fueron las relaciones entre arquitectura y política, para después realizar el estudio de los ejemplos seleccionados en los diferentes aspectos que los caracterizan, tanto sociales, ideológicos y profesionales como urbanísticos, programáticos, compositivos, constructivos y expresivos. El mecanismo de análisis se basa en la comparación por grupos de arquitecturas del mismo uso. Se inicia con el estudio de las fotografías del estado actual de todos los ejemplos encontrados, que se ordenan cronológicamente por fecha de proyecto, y en el que se comentan los aspectos derivados de su implantación urbana. Seguidamente se analizan las plantas que se ordenan no ya por un criterio cronológico sino disciplinar. A continuación, el estudio de algunos casos se completa con los alzados, siguiendo la misma pauta. Finalizamos con el análisis de la expresión como portadora de significado y entendida como la combinación de un código lingüístico y de un sistema constructivo. Se ha optado por este procedimiento porque se acepta como válido al estar trabajando con muestras homogéneas, por un lado, y porque creemos que a la hora de caracterizar un tipo de arquitectura es más completo realizar un número variado de comparaciones parciales que una sola comparación general y, sin duda, más interesante que una elemental enumeración de ejemplos.

La valoración crítica del estudio realizado conducirá al entendimiento de lo sucedido en la época y así completar el conocimiento de la arquitectura hecha en Galicia durante la Autarquía, cuya historiografía se inició tras la muerte de Franco con los primeros ensayos realizados por Carlos Almuiña y Xosé Lois Martínez en dos 
textos casi idénticos publicados en $1974^{3}$ y $1975^{4}$, José Manuel López Vázquez en 19815, María Luisa Sobrino en $1982^{6}$ y Alfredo Vigo en $1985^{7}$. En la actualidad, a pesar de que la bibliografía ha aumentado y se ha diversificado en publicaciones centradas en aspectos temáticos, geográficos, de obra y de autor, las arquitecturas que conforman este trabajo apenas han sido publicadas ${ }^{8}$, hecho que no sucede con las de otras ciudades'. Es inexplicable su ausencia en las guías de arquitectura de las diferentes ciudades gallegas publicadas por el Colegio Oficial de Arquitectos de Galicia: A Coruña en 1998, Vigo en 2003, Ferrol en 2007, Santiago en 2008 y Lugo en 2011.

\section{Relación entre política y arquitectura du- rante la Autarquía}

La mayor parte de la bibliografía arquitectónica que ha tratado los regímenes totalitarios de Europa durante el siglo XX coincide en el papel preponderante que jugó la arquitectura como símbolo y manifestación del poder que dichos regímenes querían evidenciar y mantener a cualquier precio. Cuando el análisis se personaliza en el pensamiento de los dictadores y de su idea de arquitectura, la vinculación citada es indudable. Mussolini entendía la arquitectura como un arte del Estado, al considerarla como el factor más duradero de la civilización y con una clara vocación de eternidad, tal y como se reflejó en las actuaciones llevadas a cabo durante su mandato, sobre todo en la ciudad de Roma ${ }^{10}$. Adolf Hitler también consideraba la arquitectura como arte supremo que tenía la capacidad de unificar al pueblo alemán bajo la indiscutible autoridad del régimen nazi"

En lo que a la España de la Autarquía se refiere, la asociación entre arquitectura y propaganda o entre arquitectura y símbolo del estado es algo que han defendido quienes han escrito sobre esta época, sobre todo tras la muerte de Franco como Sofía Diéguez en 1976², Alexandre Cirici en 1977³, Lluís Doménech en 197814, Gabriel Ureña en 197915, Antonio Bonet en 1981'16, Ángel Llorente en $1995^{17}$ y Ángel Urrutia en $1997^{18}$. No tiene sentido negar esa relación.

Nada más acabar la Guerra Civil se precisó el papel que el nuevo orden le reservaba a la arqui- tectura como "expresión de la fuerza y de la misión del Estado en una época determinada", tal y como se recogía en el preámbulo de la Ley por la que se creaba la Dirección General de Arquitectura ${ }^{19}$. Con este planteamiento, el paso siguiente por parte del franquismo fue intentar encontrar una arquitectura que representase esa asociación citada. Se inició la búsqueda de una arquitectura nacional con la existencia de diversas voces que reiteraban las tesis oficiales desde posturas que en ocasiones eran verdaderas soflamas patrióticas, como la expuesta en 1942 por el arquitecto Diego de Reina la Muela:

En estos tiempos de desorientación estilística, todos los arquitectos debemos cooperar, por modesta que sea nuestra aportación, a los plausibles intentos que para crear un estilo propio del nuevo Imperio Español se han emprendido por Organismos del Estado y técnicos conocedores de su misión, mediante artículos, conferencias, publicaciones, etc. ${ }^{20}$

No fue el único. Un año más tarde, Manuel García Viñolas firmaba uno de los primeros artículos que pretendían desde la teoría arquitectónica justificar lo que se estaba defendiendo desde la política, aprovechando la ocasión para rendir homenaje al dictador:

De todas las voluntades que puede tener un Caudillo, ninguna me parece tan ambiciosa como ésta de crear en el orden de la Arquitectura el estilo propio de su tiempo...la inquietud del espiritu, cuando es profunda, origina siempre un cambio de estilo en el orden de la Arquitectura... ${ }^{21}$

El Régimen quiso encontrar una arquitectura que lo definiese y que poder utilizar como símbolo de poder. Cualquier ocasión era propicia para adoctrinar a los arquitectos, tal y como hizo el Ministro de Educación Nacional en el acto de celebración del primer centenario de la Escuela de Arquitectura de Madrid: "Aliento a los arquitectos para la creación de un estilo especial característico que represente las ambiciones nacionales en tan importante ámbito de la cultura".22

Ahora bien, una vez que se fijó el "qué" el paso siguiente fue intentar definir el "cómo". Y aquí es donde encontramos una serie de reflexiones teóricas intentando responder a una pregunta muy fácil de formular y muy difícil de responder. Se buscaba algo que fuese seguro, previsible, que 
no sorprendiera. Se deseaban certezas y no se toleraban las incertidumbres. Se quería evitar lo imprevisible, lo distinto. Por todo ello se rechazó la modernidad, puesto que ofrecía posibilidades metodológicas y no respuestas ya conocidas en el momento de formular las preguntas, y se adoptó el academicismo. También porque ya se habían decantado por él tanto el nazismo alemán desde sus inicios como el fascismo italiano desde los primeros treinta, a los que el franquismo consideraba sus referentes en todos los órdenes.

Dentro de dicha corriente, interesaba que las referencias se buscasen en lo mejor de la historia de la arquitectura propia, lo que implicaba una clara aceptación de la reafirmación de lo español como base de toda manifestación cultural. Una de ellas, defendida por Antonio Palacios, fijaba el clasicismo de Juan de Villanueva, reflejo de la época gloriosa de Carlos III, como el camino a seguir, en sintonía con lo hecho en Alemania e Italia: "...La arquitectura vilanoviana es, en efecto, suma de todo severo orden, claridad eurítmica, grandiosa serenidad, verdad rigurosa, libre sin libertinaje, plena de riqueza y eficacia..." ${ }_{23}$

La verdadera razón por la que se optó por buscar una adecuación válida para ese tiempo y española de un neoclasicismo flexible, fue porque éste era el medio en la que se sentían más cómodos los arquitectos que rigieron los destinos de la arquitectura oficial desde el principio, tal y como afirmó Antón Capitel en 1995: " ... el hallazgo de la arquitectura académica como solución a la arquitectura nacional no fue una verdadera casualidad, pues tal búsqueda había sido iniciada con el fin de justificar aquel inevitable encuentro" ${ }^{24}$

Esta tesis ya había sido apuntada al final de la Autarquía por Fernando Chueca en 1953 cuando afirmó que el tradicionalismo imperante en el régimen de Franco aunaba perfectamente los intereses de la nueva política con los de los arquitectos academicistas:

El nuevo brote de tradicionalismo con que el régimen de Franco inauguró sus días fue preparado antes de su advenimiento y por hombres que ya lo estaban ensayando antes con anterioridad. Sin duda alguna, esta tendencia fue reforzada por el acontecer político y por representar mejor las bases para el nuevo Estado. ${ }^{25}$

\section{Gobiernos Civiles}

Los edificios de los Gobiernos Civiles fueron las arquitecturas que el poder político central utilizó para dejar constancia de su prevalencia sobre las instituciones de los otros poderes políticos existentes, el municipal y el provincial, cuyas sedes ya estaban construidas en las cuatro ciudades gallegas capitales de provincia ${ }^{26}$ y quisieron representar toda la fuerza del Estado con su doble carácter centralizador y omnímodo.

Una de las consecuencias de la actual división provincial, que data del año 1833, fue la del nombramiento del representante del Estado en cada una de las provincias ${ }^{27}$. Con diferentes denominaciones, será la de "Gobernador Civil" la que perdure hasta casi nuestros días, en que pasó a denominarse "Subdelegado del Gobierno"28, tras la renovación territorial definida por la Constitución de 1978. Lógicamente, un cargo político tan importante demandaba un edificio acorde a la naturaleza de la institución que representaba.

Para remediar la situación en la que la representación provincial del gobierno había tenido desde su origen un alojamiento categóricamente inferior a las otras entidades de la administración política, se inició por el gobierno la Segunda República, al amparo de la "Ley de la Previsión contra el Paro" de 1935, también conocida como "Ley Salmón" 29 una campaña de edificación de Gobiernos Civiles, con la construcción de nueve de ellos, de los que sólo estaba acabado el de Oviedo cuando estalló la Guerra Civil ${ }^{30}$. Una vez finalizada ésta y con el objetivo de evidenciar la supremacía de un régimen político dictatorial y centralista, la construcción de estos edificios se entendió como una oportunidad más de unir conceptualmente arquitectura y poder, utilizando aquélla como símbolo y manifestación de éste.

A partir de 1939 la Dirección General de Arquitectura puso en marcha un plan para que las sedes de los Gobiernos Civiles tuviesen el decoro y la dignidad que exigía dicha institución ${ }^{31}$. La puesta en marcha y desarrollo de dicho plan fueron convenientemente publicitados en las revistas de arquitectura de la época ${ }^{32}$. La situación existente era que, de las cincuenta capitales de provincia, sólo trece se hallaban en edificios propiedad del Estado. Pero, y esto es más determinante, en sólo ocho de ellas las instalaciones de 


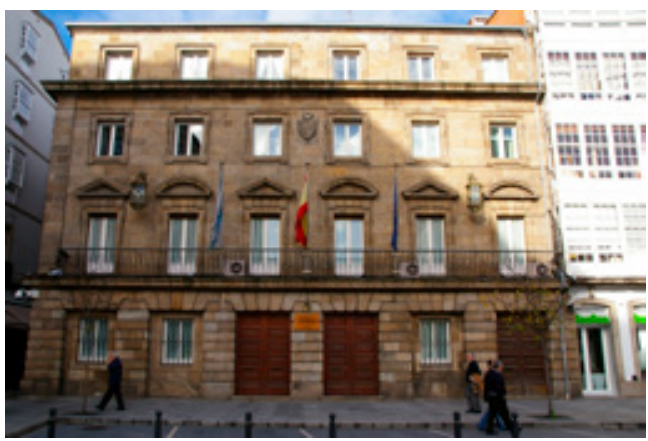

Fig. 1. Gobierno Civil de A Coruña. Ricardo Magdalena Gayán. 1944, abril. Fotografía del autor

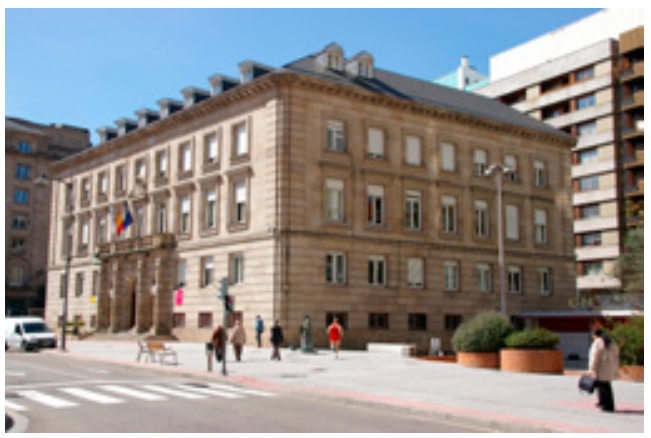

Fig. 2 Gobierno Civil de Ourense. Enrique López-Izquierdo Blanco. 1945, abril. Fotografía del autor

los Gobiernos Civiles eran adecuadas o admisibles. En las otras treinta y seis eran inadmisibles, entre las que se encontraban las cuatro capitales gallegas, por lo que se planteó como ineludible la construcción de las nuevas sedes, que se iniciará con la de A Coruña (1944 - 1947) proyectada por Ricardo Magdalena Gayán³, seguida por las de Ourense (1945 - 1947), Lugo (1946-1956) y Pontevedra (1950-1958), en las que su autor fue Enrique López-Izquierdo Blanco ${ }^{34}$ (fig. 1 a fig. 4). Ambos arquitectos tenían su despacho profesional en Madrid y ofrecían garantías suficientes a las autoridades del Ministerio del Interior al que estaba adscrita la citada Dirección General. De este modo se aseguraba un resultado esperable dentro de los cánones aceptados.

Dado el carácter que debía tener el edificio, donde radica y reside la primera autoridad provincial por encima de las demás, la situación en la que se había de construir lleva aparejada una carga semántica indudable y constituía una decisión que excede el ámbito disciplinar de la arquitectu-

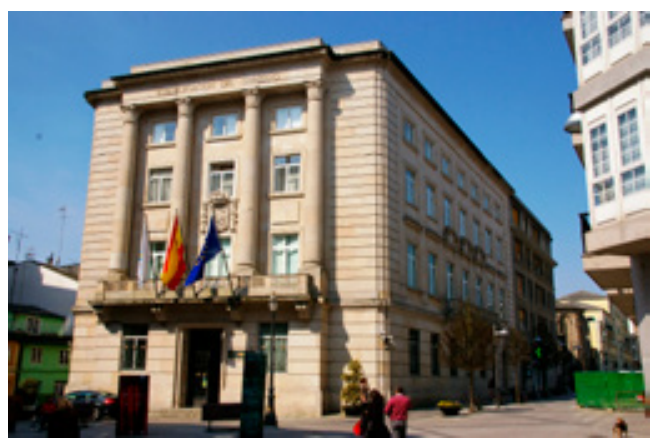

Fig. 3. Gobierno Civil de Lugo. Enrique López-Izquierdo Blanco. 1946, marzo. Fotografía del autor

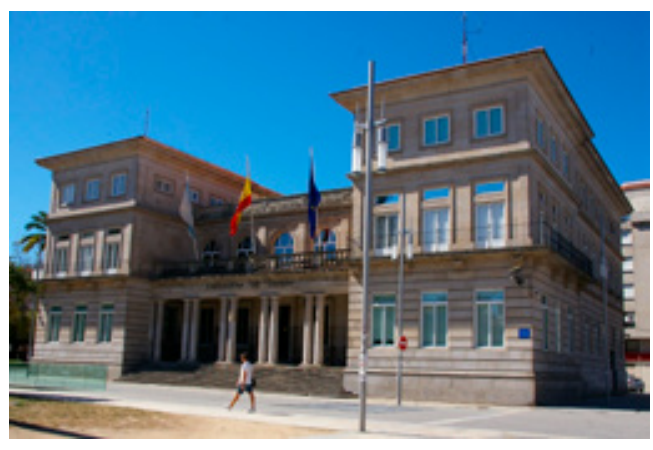

Fig. 4 Gobierno Civil de Pontevedra. Enrique López-Izquierdo Blanco. 1950, mayo. Fotografía del autor

ra y entra de lleno en el de la política. El criterio principal a cumplir era que el nuevo Gobierno Civil se había de construir en la zona más digna de la ciudad, aunque no necesariamente céntrica y evitando los lugares de uso eminentemente comercial. Además, debía tenerse en cuenta la convivencia obligada con los edificios sede de los otros dos poderes políticos preexistentes en la ciudad: el municipal y el provincial. Una vez fijada la situación, sí ya es un elemento determinante el emplazamiento del edificio, donde de nuevo se fijaron unas premisas claras: convenía que el solar fuese exento y la fachada principal debía dar a una plaza de dimensiones adecuadas a la masa del edificio, para favorecer las aglomeraciones de personas que se precisaban cuando se quería arengar a la población, a la que las autoridades consideraban como masa acrítica y disciplinada.

La combinación de los factores explicados dio como resultado la centralidad de la ubicación en las cuatro capitales gallegas, localizándose en tejidos consolidados en los casos de A Coruña, Lugo 
y Pontevedra y en una zona nueva en Ourense al norte del casco histórico de la ciudad. En el caso coruñés hubo que reformar y ampliar el edificio de la antigua Aduana Real construida en el siglo XVIII para sede del Gobierno Civil y en los otros tres las cesiones de los solares por los respectivos ayuntamientos posibilitaron la construcción de edificios de nueva planta. Ello condicionó el proyecto y determinó la distinta incidencia en la ciudad de los nuevos edificios, muy pequeña en A Coruña y más importante en Lugo, Ourense y Pontevedra, aunque en distinta medida (fig. 5).

Al consensuar las necesidades de proyecto a resolver en un edificio existente, con las pretensiones municipales coruñesas de regularización de la vía lateral que debía unir las calles Real y Avenida de la Marina, a las que dan frente las fachadas principales del edificio, se fijó para dicha calle una anchura de $5 \mathrm{~m}$ y una dirección perpendicular a la alineación de la calle Real. La consecuencia de esto, fue la necesidad de construcción de una nueva fachada. Al plantear el acceso por la calle Real, se da la extraña circunstancia de que es la fachada posterior la que posee un espacio amplio a los pies del edificio, puesto que se abre a la plaza existente por la Avenida de la Marina, prolongada visualmente por la calle ortogonal a ella, lo que determina una buena perspectiva del edificio.

En el caso lucense, el terreno que cedió el ayuntamiento se halla dentro de la muralla, delimitado al oeste por la calle Soledad, al Sur por la calle Armañá, al este por Teniente Coronel Teijeiro $y$ al norte por un edificio existente. El edificio no ocupó la totalidad del solar, dejando libre una franja al sur, al definir esta alineación con una perpendicular a la bisectriz del ángulo formado por las calles al este y al oeste, dando como resultado un pentágono irregular. Como consecuencia se generó una nueva plaza, delante del edificio a la que da la fachada principal del mismo, con la entrada y las dependencias principales, que esponjó el tejido del casco histórico lucense.

En Ourense, al tratarse de una zona nueva de la ciudad, que se estaba construyendo en la misma época, el solar cedido cumple todos los requisitos exigidos. Es exento, de geometría trapezoidal y se halla en el noroeste del Parque de San Lázaro, el nuevo centro político de la ciudad. Su singularidad se resalta al no construirse ningún otro edificio por ese lado del parque. En este caso, el Gobierno Civil no será el único edificio

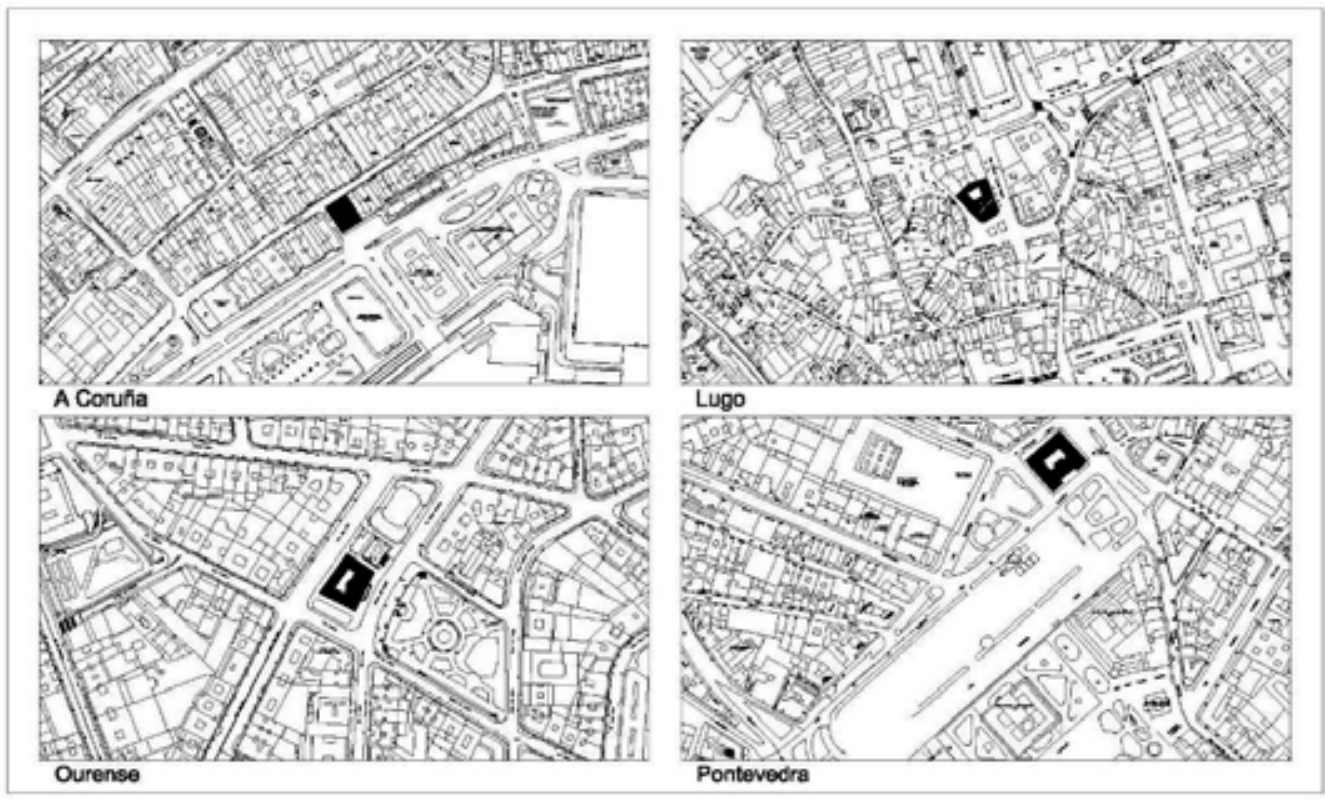

Fig. 5. Planos de situación de los Gobiernos Civiles de Galicia. Elaboración por el autor 
institucional del gobierno central que se levante en la zona. Al sur del mismo, en la esquina con la calle Juan XIII, se erigirá la sede del Instituto Nacional de Previsión ${ }^{35}$ y enfrente, al otro lado del parque, la Casa Sindical Provincial, que analizaremos más adelante. De esta manera, el régimen gobernante evidenció su presencia en la ciudad de modo claro, convirtiéndose el conjunto en una muestra del nuevo concepto de ciudad a él vinculado. Lógicamente, la fachada principal del edificio da frente al parque.

A diferencia de las tres ciudades anteriores, en los que los nuevos edificios están separados de las sedes de los poderes municipal y provincial, en Pontevedra se produjo un caso de convivencia en un mismo espacio público de los tres edificios, definiendo sin ninguna duda el centro cívico por excelencia de la ciudad. El solar cedido por el ayuntamiento es también exento como el orensano, de planta rectangular y emplazado en el vértice noroeste de la Alameda que tiene una planta circoagonal, con su directriz mayor en la dirección noreste-suroeste, con el Ayuntamiento situado al noreste y el Instituto y el Palacio de la Diputación definiendo el lado sureste. En el mismo lado que el Gobierno Civil, pero en una posición más retrasada se halla el Cuartel de San Fernando, actual Facultad de Bellas Artes. En una primera propuesta de 1945 del arquitecto P. Durán, el edificio ocupaba este solar pero su fachada principal no daba a la Alameda sino a la Plaza de España, lo que sin duda fue una de las causas de su rechazo por las autoridades municipales ${ }^{36}$, al entender que una fachada lateral no podía dar frente al espacio público citado. López-Izquierdo corrigió este evidente error proyectual y su propuesta en este aspecto fue sensata a la vez que lógica, al colocar su edificio mirando de frente a la Alameda y no de lado.

El emplazamiento del edificio y la regularidad o irregularidad en la geometría del solar condicionarán su composición en la que se siguen los principios academicistas comentados anteriormente. Entre ellos destaca la utilización de la simetría como herramienta de ordenación planimétrica, aunque con distinto alcance en cada uno de los casos, que podemos denominar simetría total, simetría parcial y simetría elemental. Definimos la simetría como total cuando abarca la planta ente-

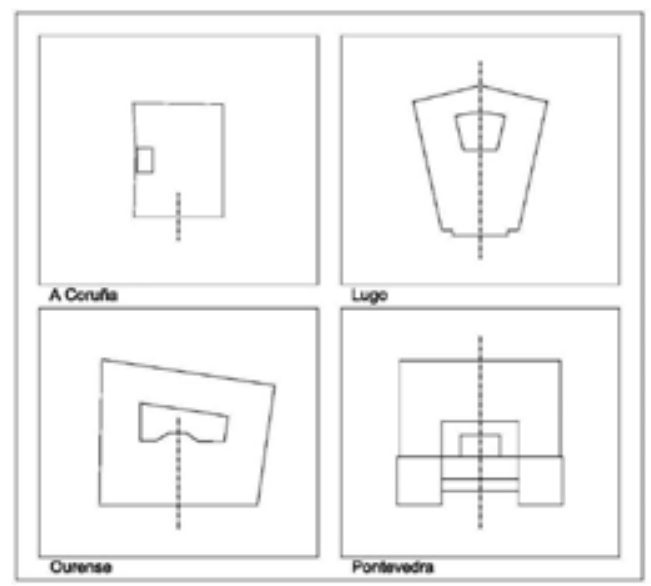

Fig. 6. Esquemas planimétricos a la misma escala de los Gobiernos Civiles de Galicia. Elaboración por el autor

ra, como en los proyectos de Lugo y Pontevedra. La simetría es parcial cuando se utiliza sólo en las primeras crujías hasta el patio del edificio como en Ourense. Por último, la simetría elemental se reduce a la composición de la fachada, como en el caso coruñés (fig. 6).

Podemos calificar el programa de un Gobierno Civil como complejo puesto que combina diferentes usos simples necesarios e interrelacionados entre sí para la correcta solución del encargo: el representativo, que abarca desde la entrada y la escalera de honor a las zonas de trabajo del Gobernador y el salón de sesiones y recepciones; el administrativo, con despachos y oficinas para el Secretario General y diversos negociados; el residencial, que resalta la jerarquía al separar las viviendas para los dos máximos funcionarios citados y un apartamento para un huésped de honor de las viviendas para personal subalterno. Los tres usos anteriores se completan con las dependencias necesarias para instalaciones y servicios, desde el garaje hasta el retén de guardia y los calabozos.

La diversidad de usos implica la necesidad de varias entradas, marcándose una nítida prelación entre ellas, estando la principal en la fachada homónima. El resto tiene un carácter secundario, independientemente de su uso público, de acceso a las dependencias policiales o administrativas, 0 privado, de acceso a las viviendas. Si observamos las plantas bajas de los cuatro edificios podemos comprobar que sólo en el caso de Lugo las en- 
tradas secundarias mantuvieron el criterio de simetría en planta (fig. 7). En el edificio orensano hay que añadir la entrada de vehículos se dispuso en el centro de la fachada opuesta a la principal debido a que no tenía ningún otro condicionante al ser un edificio exento (fig. 8).

La misma solución se adoptó para el de Pontevedra (fig. 9). La comunicación directa con los salones y despachos de mayor representación que están ubicados en la planta primera, definida como noble en los planos de los proyectos, se resuelve con la escalera de honor que ha de estar necesaria y estrechamente enlazada con la entrada principal. En los cuatro casos tienen un tratamiento monumental debido a su importancia, proyectándose como escaleras imperiales en las sedes coruñesa (fig. 10) y lucense. Análogamente a lo hecho con las entradas, se dispusieron otras escaleras secundarias, que, en algunos casos no

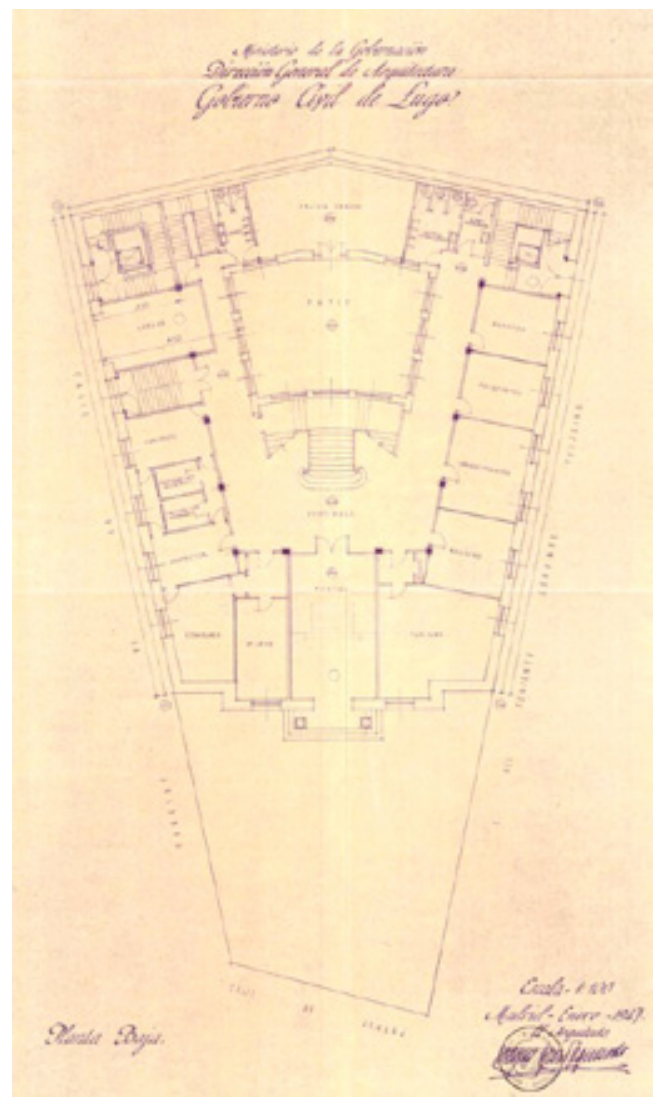

Fig. 7. Gobierno Civil de Lugo. Planta baja. Enrique LópezIzquierdo Blanco. 1946, marzo. AGA 04078 26/15893 recorren toda la altura del edificio, como las que unen las plantas bajas con los semisótanos. De las ascendentes que arrancan en la planta de acceso, se mantuvo de muevo la disposición simétrica en los edificios de Lugo y Pontevedra.

Vinculado a la escalera de honor y para su iluminación se halla el patio del edificio, dispuesto sobre ella en el edificio coruñés y a continuación en los otros tres, generando en ellos una secuencia planimétrica: entrada - escalera - patio. En los casos lucense y orensano, se mantiene esa secuencia en la planta noble, con el salón de recepciones que se dispone con su balcón encima de la entrada. En el resto de lados del patio hay huecos de iluminación y ventilación de corredores o dependencias auxiliares, según los casos.

La organización vertical del programa es idéntica en los cuatro edificios. En la planta de acceso se disponen la entrada principal comunicada con el arranque de la escalera de honor, y una serie de dependencias destinadas a las fuerzas de seguridad. Los locales considerados impropios de figurar en planta baja se relegan a una planta semisótano, de dimensiones siempre menores. La planta noble va vinculada al carácter político representativo, con las dependencias públicas del gobernador, completadas con las del secretario general. En la segunda planta se combinan usos administrativos con los residenciales. Esta es la planta de remate en el Gobierno Civil de Pontevedra. No sucedió lo mismo en los otros tres, donde sobre ella se dispuso una planta de ático de uso residencial, retranqueada en el caso coruñés y

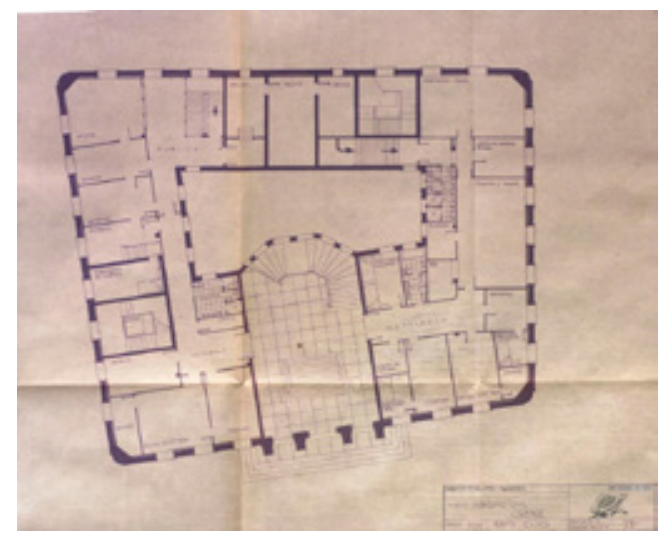

Fig. 8 Gobierno Civil de Ourense. Planta baja .Enrique LópezIzquierdo Blanco. 1945, abril. AGA 04078 26/15896 
abuhardillada con mansardas en el de Ourense, aunque no estuviesen previstas en el proyecto; en Lugo se proyectó una tercera planta que se completará parcialmente con un ático en la parte posterior del edificio.

Desde un punto de vista semántico nos encontramos con cuatro ejemplos en los que se entiende que la arquitectura debe estar al servicio de la ideología dominante en el momento. Esta premisa debe verificarse en lo que la población sienta y entienda al contemplar los edificios de los Gobiernos Civiles. Por tanto, el objetivo último de la institución cliente es que la expresión del edificio en su doble componente material y lingüística debe conseguir que el mensaje quede claro, evitándose toda confusión y remarcando la severidad inherente a su destino.

En el edificio coruñés estaban protegidas las fachadas a la calle Real y la Avenida de la Marina, por lo que era obligatoria su conservación. El resto fue proyectado como un edificio de nueva planta. Dichas fachadas estaban construidas en piedra de sillería y sólo necesitaban una discreta reparación. Ricardo Magdalena proyectó en este mismo material la nueva fachada transversal en lugar de la mampostería encalada del edificio original. Al producirse el vaciado fue precisa la construcción de una nueva estructura proyectada

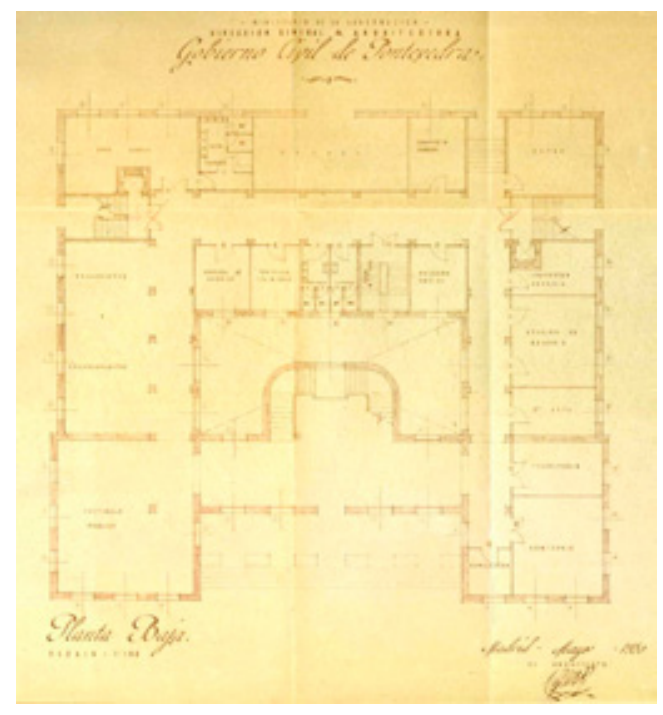

Fig. 9 Gobierno Civil de Pontevedra. Planta baja. Enrique López-Izquierdo Blanco. 1950, mayo. AGA 04078 26/15900 en hormigón armado, definida por ocho pares de soportes en la zona central que conforman un sistema estructural propio, que con los muros perimetrales constituyeron los apoyos de los nuevos forjados. En los otros tres, López-Izquierdo adoptó el mismo sistema constructivo: estructura de hormigón armado, definiéndose las líneas de pilares perfectamente reconocibles en las plantas del edificio, con una disposición regular en la que las crujías resultantes definen la composición planimétrica y la distribución de las diferentes dependencias. Las fachadas son de hormigón, chapadas de piedra y con despiece almohadillado en los elementos principales de la composición: cuerpo basamental en los tres edificios y remarcando los cuatro ángulos principales en Lugo y Ourense. El resto de elementos tales como guarniciones de huecos, balaustradas, ménsulas, impostas y cornisas se ejecutarán también en piedra, utilizando conscientemente toda la carga significante que este material ha tenido desde siempre.

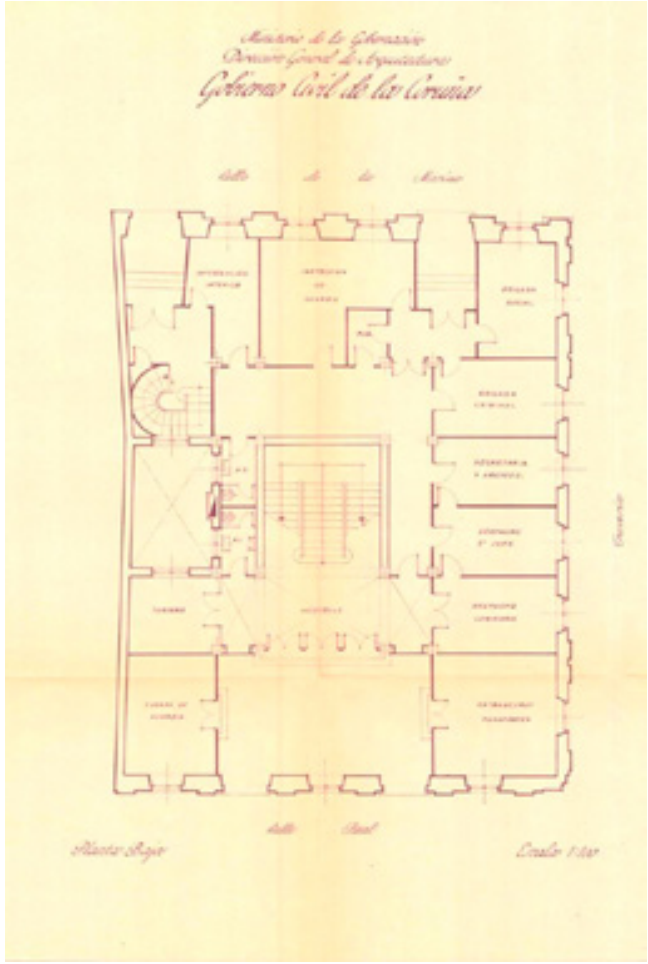

Fig. 10 Gobierno Civil de A Coruña. Planta baja. Ricardo Magdalena Gayán. 1944, abril. AGA 04078 26/15870 
Dado el objetivo perseguido, el material utilizado tenía que acompañarse de un lenguaje que tampoco ofreciese dudas, por lo que se escogió el código clásico que los arquitectos manejaban con comodidad ya desde su etapa de formación académica. Ineludible en el caso coruñés y opcional en las otras tres ciudades, el manejo de la sintaxis pone a prueba la capacidad y el talento de los arquitectos.

Enrique López-Izquierdo planteó en Ourense una solución elegante para la entrada principal con la utilización de una serliana y evidenció oficio en la composición de los cuatro alzados: mantuvo como fija la dimensión de los huecos y variable la del entrepaño en cada uno de los frentes, teniendo la cautela de igualar la distancia entre el punto central de los arcos con los que se resuelven los enlaces entre las fachadas y el primer hueco por cada lado, donde sabía que la percepción podía ser más precisa, al poder tomar referencias visuales en los dos planos que se unen conformando la esquina.

En el edificio de Lugo reforzó la fachada principal con un tetrástilo de orden gigante, no previsto en la primera propuesta ${ }^{37}$, que al arrancar de la primera planta y tener un balcón corrido que impide verlo en su totalidad, es más efectista que efectivo; las fachadas laterales son discretas, resueltas con un elemental dibujo de huecos, sólo alterado con la inclusión de frontones curvos sobre los que dan al balcón que se construye en la fachada noreste. En este edificio y en el orensano el empleo de elementos secundarios de la figuración es simplemente correcto.

En Pontevedra propuso un edificio volumétricamente más complejo. Partió de una entrada monumentalizada con un pórtico de columnas pareadas exentas rematado por una balaustrada que defiende una terraza delimitada por una galería arqueada; todo ello flanqueado por dos volúmenes prismáticos a modo de torreones, dando como resultado un conjunto poco acertado debido a la ruptura de la verticalidad de los mismos al tener la planta baja almohadillada, un balcón corrido en primera planta que vuelve sobre el lateral, compitiendo con la balaustrada central y resaltando excesivamente la imposta entre las plantas primera y segunda. Además, en los alzados laterales la variación de dimensión de los torreones con el resto del volumen que se prolonga hacia la parte posterior es tan pequeña que en la visión diagonal se pierde el efecto pretendido. Esto último queda aún más marcado por la presencia de la horizontalidad que unifica volumétricamente todas las fachadas mediante la continuidad de impostas y cornisa que las recorren.

Por el contrario, Ricardo Magdalena resolvió de modo brillante la comentada exigencia de la conservación de las fachadas del edificio coruñés, que sólo mantienen la dimensión vertical hasta la planta noble. Sutilmente, unificó alturas disminuyendo la de los huecos de planta segunda en la Marina y subiendo los de la calle Real, aumentando las basas de las pilastras jónicas de esta última con cuidado de no estirarlo excesivamente, para poder montar sobre ellas el entablamento y la cornisa, perdiéndose el primero al volver en la fachada lateral de nueva creación y continuándose la segunda en la totalidad del edificio. En esta fachada, redujo el apilastrado, marcándose sólo los huecos extremos, a modo de transición con la fachada de la Marina que carece del mismo y de entablamento. Todo lo anterior condujo a una elegante diferenciación en el tratamiento de las esquinas, claramente legible en la planta, que consistió en una transición elemental entre dos planos entra las fachadas de la Marina y la lateral, y otra más compleja entre ésta y la de la calle Real mediante la inclusión de una serie de quiebros para disimular la ya comentada interrupción del entablamento. La planta del ático, construida para poder completar el programa exigido, se retiró discretamente del plano de fachada y se dimensionó de modo correcto, consiguiendo un conjunto equilibrado.

En la actualidad los cuatro edificios mantienen su carácter institucional puesto que en ellos se halla la sede de la Subdelegación del Gobierno en cada capital de provincia. Las modificaciones introducidas en ellos sólo son relevantes en el caso coruñés donde la transformación en principal de la fachada a la Avenida de la Marina implicó la inversión del sentido de la escalera de honor con respecto a lo proyectado.

\section{Casas Sindicales}

Tras la victoria en la Guerra Civil el control político por parte del Régimen quiso abarcar to- 
dos los estamentos del Estado, sobre todo los de aquellos que de alguna manera podían constituir un posible frente de oposición política, entre los que se encontraban las asociaciones de trabajadores. Una vez proscritas y pasadas a la clandestinidad las organizaciones sindicales republicanas, como la anarquista Confederación Nacional del Trabajo (C.N.T.) y la socialista Unión General de Trabajadores (U.G.T.), la representación sindical debía ser reflejo de la organización política del Nuevo Estado con sus atributos de unidad, totalidad y jerarquía. Por imposición legal ${ }^{38}$, a partir de 1940 la única entidad reconocida por el Estado para vehicular la comunicación en ambos sentidos, transmitiendo las aspiraciones y necesidades de los trabajadores, por un lado, y las directrices del Estado, por otro, será la Organización Sindical de F.E.T. y de las J.O.N.S., conocida popularmente como "Sindicato Vertical" Todas las asociaciones de productores, que es como se denominaba en la ley a los trabajadores, quedaron sometidas a la disciplina del Movimiento, bajo el control de la Delegación Nacional de Sindicatos. Ésta quiso tener representación en todo el territorio nacional por medio de las conocidas como "Casa Sindical", que se organizaron jerárquicamente de acuerdo con su ámbito de intervención, siendo las más importantes las provinciales que se ubicaron en las capitales de provincia, seguidas de las comarcales que lo hicieron en las ciudades importantes que no tenían ese rango. Las Casas Sindicales fueron el segundo grupo de arquitecturas tras los Gobiernos Civiles, que evidenciaron la presencia constante del poder político que ejercía un control total, en este caso sobre las relaciones económicas que posibilitan el desarrollo de cualquier actividad.

En el ámbito temporal de estudio, en Galicia se proyectaron o construyeron las Casas Sindicales Provinciales de A Coruña y Ourense y las Casas Comarcales de Vigo y Ferrol. La única que se conserva es la Casa Sindical Provincial de Ourense (fig. 11), proyectada en noviembre de 1947 por Rafael Aburto Renobales, arquitecto vinculado al Sindicato ${ }^{39}$, y Mariano Rodríguez Sanz, arquitecto municipal.

A la hora de decidir la ubicación de las mismas, los criterios fueron diferentes según los casos. La del edificio de Ourense es más acorde al estatus

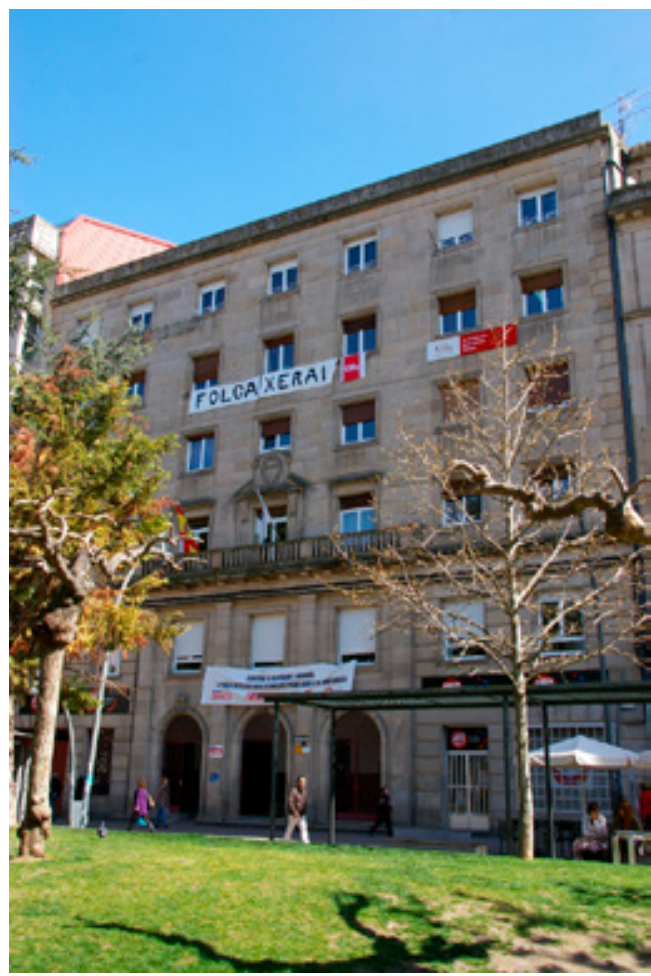

Fig. 11. Casa Sindical de Ourense. Rafael Aburto Renobales y Mariano Rodríguez Sanz. 1947, noviembre. Fotografía del autor

que debe representar puesto que el solar elegido da frente al Parque de San Lázaro, cuyo nuevo papel urbano ya se ha señalado, con el Gobierno Civil situado en el lado opuesto, próximo a la sede del Instituto Nacional de Previsión, asignando entre los tres edificios un nuevo carácter político a esa parte de la ciudad.

En los otros casos, las razones fueron de oportunidad de distinta naturaleza al plantearse en solares ya edificados o en obras. Las de las Casas Sindicales de A Coruña y Vigo tenían una segunda intencionalidad política, puesto que quiso dejar patente la idea de supremacía del bando vencedor, ya que se apropiaron de lugares vinculados a los derrotados en la Guerra Civil. La de A Coruña ocupó un solar entre medianeras con frente a las calles Federico Tapia y Pardo Bazán perteneciente a la antigua C.N.T., expropiado por el gobierno municipal y cedido al Sindicato Vertical. Las obras ya estaban iniciadas y se aprovecharon en parte. Su proyecto fue redactado 
en octubre de 1943 por Juan González-Cebrián, a la sazón arquitecto de la Obra Sindical del Hogar. En el caso vigués, con proyecto de marzo de 1945 elaborado por Enrique Álvarez-Sala, se eligió un solar en parte edificado y que tenía una construcción que era la antigua Casa del Pueblo en la calle García Barbón. Dado el mal estado se proyectó el derribo de lo existente y la edificación de nueva planta en todo el solar.

La Casa Sindical Comarcal de Ferrol fue proyectada para adaptarse al edificio del antiguo Ayuntamiento una vez que éste se trasladó a la nueva sede de la Plaza de Armas. Ocupaba una manzana triangular definida por las actuales calles Carmen, Manuel del Cal y Cantón de Molíns, a la que daba la fachada principal. Es una actuación con una marcada significación política al vincular al Sindicato con un edificio con gran carga afectiva en la ciudad natal de Franco. El documento fue redactado en julio de 1953 por Juan González-Cebrián. Fue una intervención menor en la que las nuevas dependencias resultado de las demoliciones precisas para acomodar el programa de necesidades al nuevo uso, se adaptaron a los huecos existentes y no se modificaron las fachadas El edificio fue demolido y reemplazado por otros de uso residencial.

Los solares de A Coruña y Ourense son entre medianeras, con frente a una calle éste último y con frente a dos el primero, con las entradas en los lados cortos. En la planta baja del edificio coruñés (fig. 12) la relación de éstas con las escaleras nos marca cuál es la principal, que da frente a una de tipo imperial colocada a eje y situada antes del salón de actos que se dispuso de modo transversal al solar y con accesos poco representativos por un corredor con dimensión insuficiente. En la otra entrada se pierde la secuencia entrada-escalera al ocupar ésta una posición lateral. En Ourense la entrada por un solo lado obliga a diferenciar los accesos a las tres partes principales que conforman el programa, reservando los huecos centrales para la Delegación y destinando los extremos al Hogar del Pro-

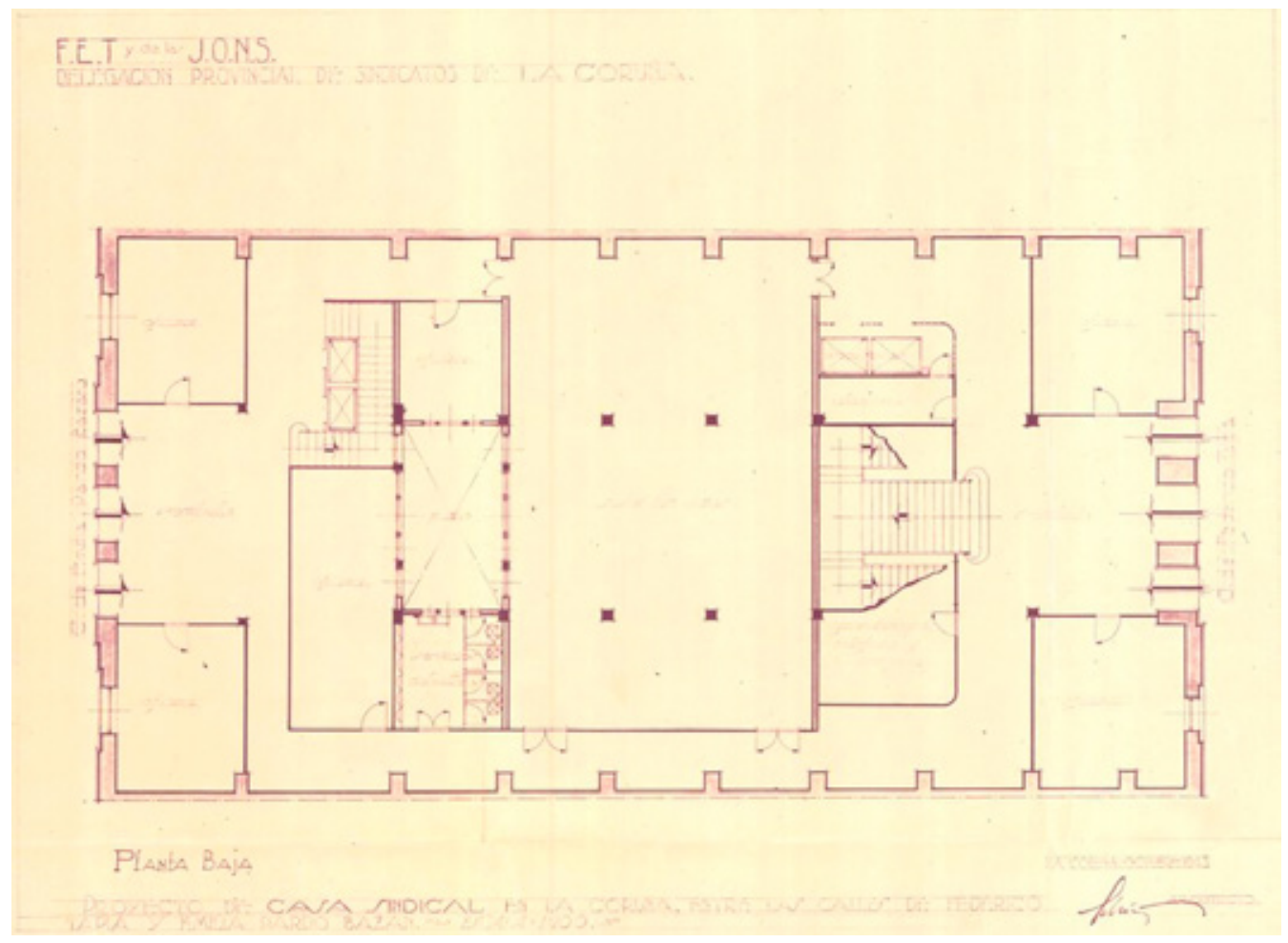

Fig. 12. Casa Sindical de A Coruña. Planta Baja. Juan González Cebrián. 1943, octubre. AGA 34/239 593 


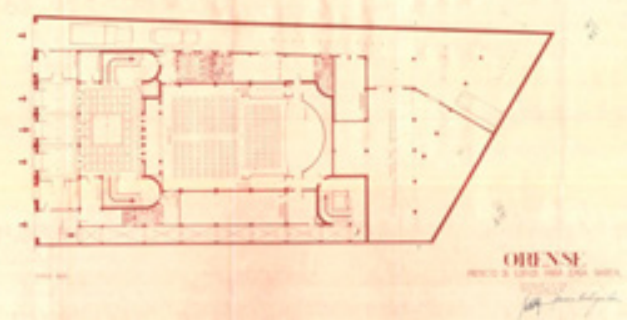

Fig. 13. Casa Sindical de Ourense. Planta Baja. Rafael Aburto Renobales y Mariano Rodríguez Sanz. 1947, noviembre. AGA $34 / 239593$

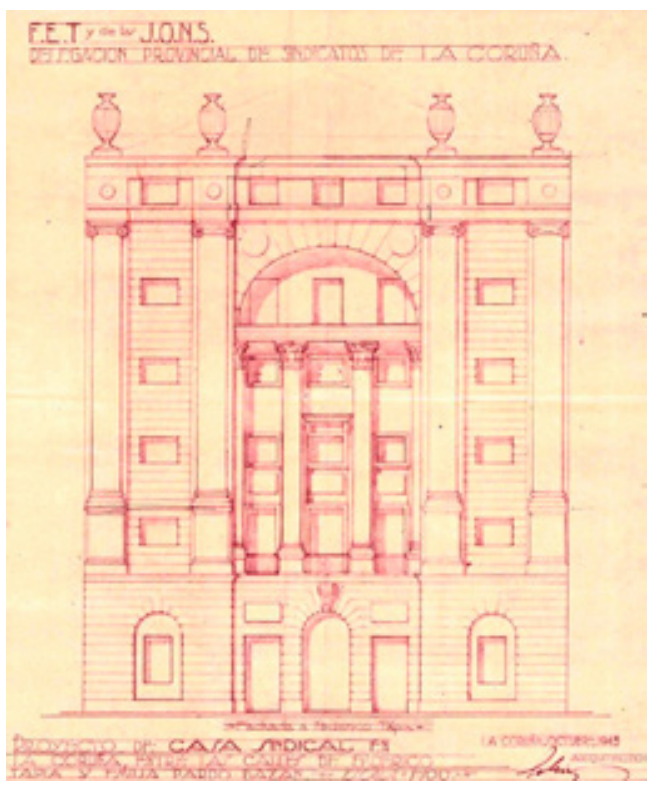

Fig. 14. Casa Sindical de A Coruña. Alzado. Juan González Cebrián. 1943, octubre. AGA 34/239 593

ductor y a la Unión Territorial respectivamente, conformando una simetría elemental. El acceso ceremonial secuenciado culmina en el gran salón de actos cuyo foyer está flanqueado por los principales núcleos de escalera. La adecuación entre la regularidad de los elementos centrales y la irregularidad del solar, resuelta con la deformación de elementos secundarios, evidencia el oficio del arquitecto en la resolución de la planta (fig. 13).

La fachada principal del edificio coruñés fue organizada según una ordenación que siguió fidedignamente los postulados de la arquitectura academicista por medio de una doble composición tripartita tanto en vertical como en horizontal. En vertical, un cuerpo bajo almohadillado soporta

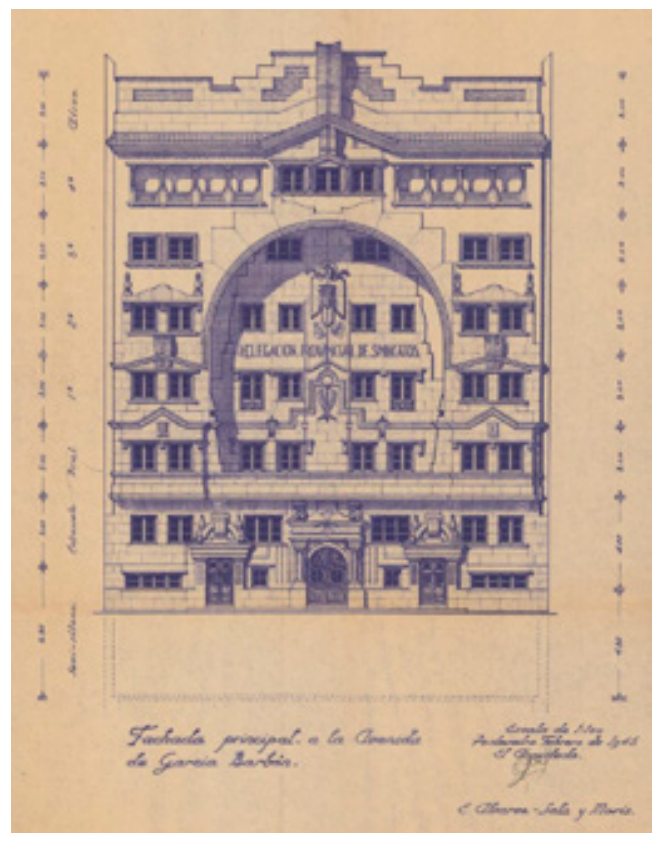

Fig. 15. Casa Sindical de Vigo. Alzado. Enrique Álvarez-Sala Moris. 1945, marzo. AGA 34/784 2

uno central de cuatro alturas modulado por un tetrástilo gigante de orden jónico que se remata con un entablamento de una planta. En horizontal, el tramo central es más ancho y arranca con una serliana en planta baja, para en el cuerpo intermedio organizar un fantasioso dístilo soporte de un dintel y un arco (fig 14). Este es un buen ejemplo de cómo conjugar la exigencia de representatividad de un edificio singular con semejante carga política implícita, con la realidad de un solar entre medianeras, buscando la respuesta en esa exhibición figurativa, que después en obra se redujo radicalmente. El edificio fue derribado y reemplazado por otro de uso residencial.

La misma exigencia existe en el caso de Vigo. En el alzado proyectado (fig. 15) se puede observar un planteamiento similar al coruñés al optar por un tratamiento de la fachada como un gran arco de un solo vano, acompañado de una figuración regionalista en lugar de la clasicista del edificio coruñés, que resuelve con un aparataje excesivo el tratamiento de todos los huecos. Una doble galería en la última planta flanqueando un hueco central rematado en frontón constituye el límite superior de una composición fallida en sus 
proporciones y figuraciones. Este proyecto fue rechazado y se construyó más tarde otro edificio en una esquina de la misma calle, más discreto en todos sus aspectos y que aún se conserva, siendo la actual sede de la U.G.T.

En Ourense la respuesta al problema de no poder hacer un edificio exento fue mucho más contenida que en las soluciones anteriores, con una fachada principal de evidente composición academicista, tanto en la primera propuesta como en la definitiva, mejor proporcionada al elevarse una planta. El tratamiento del cuerpo basamental permite una fácil legibilidad de los accesos a las distintas partes del edificio. El tratamiento figurativo huye de la exacerbación de los casos coruñés y vigués y se caracteriza por su sobriedad, destacando el apilastrado tetrástilo que enmarca la arquería protagonista del tramo central de la planta baja y el frontón que señala el hueco principal de la planta noble. Ejemplo habitual de solución constructiva aceptada sin problemas, puesto que una estructura de hormigón armado se vistió con la utilización en la fachada de la piedra granítica propia de la región, con lo que se resolvieron simultáneamente las exigencias de adaptación al medio urbano y de significación política, al transmitir el material empelado severidad y duración, a la vez que posibilitó el tratamiento figurativo empleado. Hoy en día conviven en el edificio las sedes provinciales de diversas organizaciones sindicales como C.I.G., CC. OO., U.G.T. y U.S.O. con la delegación del Fondo de Garantía Salarial del Ministerio de Empleo y Seguridad Social.

\section{Conclusiones}

Los edificios que se conservan de la arquitectura institucional promovida en Galicia durante la Autarquía se han convertido en elementos fundamentales en sus respectivas áreas de influencia y, dado el tiempo transcurrido desde su construcción, ya pertenecen a la memoria colectiva de sus ciudades al formar parte de su paisaje urbano consolidado.

Respondieron perfectamente a su cometido, desde la selección de su situación y emplazamiento hasta su resolución proyectual, en la que la expresión final de esas arquitecturas y por tanto su carácter fue el resultado de aunar una figuración que tomó prestadas citas históricas de códigos pretéritos, con una solución material tradicional en su piel que camufló una construcción en la que se empleó la más alta tecnología en estructuras e instalaciones. El academicismo inicial de su composición devino en una organización en planta y sección que resolvió los diversos programas complejos de un modo eficaz. La calidad de los resultados fue diversa, evidenciando de este modo el distinto conocimiento y oficio de los arquitectos que los idearon, todos ellos vinculados a las respectivas instituciones, definiendo un modo de actuación habitual en su momento, en el que nada podía escapar a un control previo que asegurase el resultado pretendido.

Las arquitecturas institucionales políticas en Galicia mantienen hoy en día su papel representativo, aunque en menor medida que el original debido a la nueva organización política del Estado, basada en principios democráticos, afortunadamente distantes y distintos de los dictatoriales que caracterizaron la época en la que se construyeron. 


\section{NOTAS}

1 Nos referimos a las ciudades de A Coruña, Ferrol, Santiago, Lugo, Ourense, Pontevedra y Vigo.

2 Braunfels, Wolfgang. 1987 "Dominio político y arquitectura". In Urbanismo occidental, 11-18. Madrid: Alianza Forma.

${ }^{3}$ Almuiña Diaz, Carlos and Martínez Suárez, Xosé Lois. 1974 "Arquitectura". In Gran Enciclopedia Gallega, 8991. Santiago: Silverio Cañada.

${ }^{4}$ Almuiña Diaz, Carlos and Martínez Suárez, Xosé Lois. 1975. "El período 1936-1950". In Rafael González Villar e a súa época. Vigo: C.O.A.G.

${ }^{5}$ López Vázquez, José Manuel. 1981. "La arquitectura gallega contemporánea". In Galicia en el siglo XX, 1137-1153. Barcelona: Nauta.

${ }^{6}$ Sobrino Manzanares, María Luisa. 1982. "El siglo XX: Arquitectura". In Historia del arte gallego, 423-436. Madrid: Alhambra.

${ }^{7}$ Vigo Trasancos, Alfredo. 1990. "A arquitectura do século XX". In $A$ arte galega. Estado da cuestión, 393-420. A Coruña: Publicacións do Consello da Cultura Galega.

${ }^{8}$ Sólo aparecen mencionados, sin citar su autor, los Gobiernos Civiles de Ourense y Pontevedra en Seara Morales, lago. 1993. "De la arquitectura racionalista a la arquitectura de la Autarquía". In Arte contemporáneo, 328351. A Coruña: Hércules de Ediciones, S.A.

${ }^{9}$ Véase, a modo de ejemplo, Vázquez Astorga, Mónica and Yeste Navarro, Isabel A. 2013. "El Gobierno Civil de Zaragoza y su sede institucional". Artigrama 26: 743-768.

${ }^{10}$ Kruft, Hanno Walter. 1990. "Italia: futurismo y racionalismo". In Historia de la teoría de la arquitectura. Desde el siglo XIX hasta nuestros días, 687704. Madrid: Alianza Editorial.

${ }^{11}$ Adam, Peter "Hitler y los arquitectos". 1992. In El arte del Tercer Reich, 206-227. Barcelona: Tusquets Editores.

12 Diéguez Patao, Sofía. 1976 "Nueva política, nueva arquitectura". Arquitectura 199: 57-62.
${ }^{13}$ Cirici Pellicer, Alexandre. 1977. La estética del franquismo. Barcelona: Gustavo Gili.

${ }^{14}$ Doménech Girbau, Lluís. 1978. Arquitectura de siempre. Los años 40 en España. Barcelona: Tusquets Editores.

${ }^{15}$ Ureña Portero, Gabriel. 1979. Arquitectura y Urbanistica Civil y Militar en el Período de la Autarquía (1936-1945), Madrid: Istmo.

${ }^{16}$ Bonet Correa, Antonio. 1981. "Espacios arquitectónicos para un nuevo orden". In Arte del franquismo, 1146. Madrid: Cátedra.

17 Llorente Hernández, Ángel. 1995. Arte e ideología en el franquismo (1936-1951). Madrid: Visor.

${ }^{18}$ Urrutia Núñez, Ángel. 1987. "La arquitectura de la Autarquía (19401950)". In Arquitectura del siglo XIX, del modernismo a 1936 y de 1940 a 1980. Zaragoza: Exclusivas de Ediciones S. A.

19 Jefatura del Gobierno Nacional. 1939. "Ley de 23 de septiembre de 1939 creando la Dirección General de Arquitectura". Boletín Oficial del Estado, September 30, 1939: 5427.

${ }^{20}$ Reina de la Muela, Diego de. 1942. "Divagaciones arquitectónicas. Los imperios y su estilo". Reconstrucción 23: 193-194.

${ }^{21}$ García Viñolas, Manuel Augusto. 1943. "Sobre la creación de los estilos arquitectónicos". Revista Nacional de Arquitectura 18-19: 243.

22 Ibáñez Martín, José. "Discurso del Ministro de Educación Nacional". Revista Nacional de Arquitectura 38: 36-37.

${ }^{23}$ Palacios Ramilo, Antonio. 1945. "Ante una moderna arquitectura". Revista Nacional de Arquitectura 47-48: 405-413.

${ }^{24}$ Capitel, Antón. 1995. "La arquitectura española del historicismo tardío en el período posterior a la Guerra Civil: 1939 - 1949". In Arquitectura española del siglo XX, 357-383. Madrid: Espasa Calpe.

${ }^{25}$ Chueca Goitia, Fernando. 1988. "Manifiesto de la Alhambra". Arquitectos 154: 100-111. Publicación del texto homónimo de 1953.
${ }^{26}$ Fernández Fernández, Xosé. 1995. "Arquitectura institucional". In Arquitectura del Eclecticismo en Galicia, 29-174. A Coruña: Universidade Da Coruña.

27 Dóriga Tovar, César, 1967. "El cargo de Gobernador Civil y Jefe Provincial del Movimiento en el nuevo estado español". Revista de estudios políticos 156: $145-168$.

${ }^{28}$ Jefatura del Estado. 1997. "Ley 6/1997, de 14 de abril, de Organización y Funcionamiento de la Administración General del Estado: Artículo 29. Los Subdelegados del Gobierno". Boletín Oficial del Estado, April 15, 1997: 11762-11763.

${ }^{29}$ Ministerio de Trabajo, Sanidad y Previsión. 1935, "Ley de la Previsión contra el Paro: Artículo $6^{\circ}$. Edificios Públicos". Gaceta de Madrid, June 26, 1935: 2443. El titular del Ministerio era Federico Salmón Almorín

${ }^{30}$ Equipo redactor. 1947a. "Mejoras de los edificios destinados a Gobiernos Civiles". Boletín de Información de la Dirección General de Arquitectura 3: 11-14

31 Equipo redactor. 1942. "Plan Nacional de Gobiernos Civiles". Revista Nacional de Arquitectura 10-11: 31.

${ }^{32}$ Las ciudades cuyos edificios de Gobierno Civil se publicaron fueron los siguientes: Las Palmas y Pamplona: Equipo redactor. 1942. "Plan Nacional de Gobiernos Civiles". Revista Nacional de Arquitectura 10-11: 31. Toledo: Equipo redactor. 1944. "Construcción del nuevo Gobierno Civil de Toledo en la Plaza de Zocodover". Reconstrucción 46: 277-286. Badajoz y Cuenca: Equipo redactor. 1947a. "Mejoras de los edificios destinados a Gobiernos Civiles". Boletín de información de la Dirección General de Arquitectura 3: 11-14. León: Equipo Redactor. 1947b. "Noticias". Boletín de información de la Dirección General de Arquitectura 4: 35. Murcia: Fisac Serna, Miguel. 1948. "Anteproyecto de Palacio Municipal y Gobierno Civil en Murcia". Revista Nacional de Arquitectura 75: 91-94. Santander: Fernández Huidobro, Rafael. 1948. "Gobierno Civil". Revista Nacional de Arquitectura 75: 125-127.

33 Ricardo Magdalena Gayán fue el autor, entre otras obras, del Ayunta- 
miento de Zaragoza con Alberto Acha Urioste y Mariano Nasarre Audera, ganadores del concurso en 1941; de la ampliación y de la reforma de San Mamés con De Miguel y Domínguez Salazar, en 1951. Fue uno de los firmantes del Manifiesto de la Alhambra en octubre de 1952

${ }^{34}$ Enrique López-Izquierdo Blanco fue profesor de la Escuela de Aparejadores de Madrid de 1939 a 1970. Realizó obras de reforma en diversos edificios de Madrid como el Palacio de la Prensa o el Teatro Albéniz. Además de los tres gallegos, fue el autor del Gobierno Civil de Badajoz, cuyas plantas esquemáticas se publicaron en Equipo redactor. 1947. "Mejoras de los edificios destinados a Gobiernos Civiles".
Boletín de información de la Dirección General de Arquitectura 3: pp. 11-14.

${ }^{35}$ El edificio de la Delegación Nacional de Previsión, hoy Tesorería General de la Seguridad Social, fue proyectado por Eduardo de Garay Garay en febrero de 1947.

${ }^{36}$ Otra de las causas la indicó Enrique López-Izquierdo Blanco en la Memoria del Proyecto de mayo de 1950, cuando escribió refiriéndose a la propuesta de P. Durán: "La austeridad como se proyectó no fué del completo gusto de las Autoridades Locales, representando el sentir y gusto de sus habitantes, no ya de la ciudad, sino de aquella provincia, donde impera una arquitectura de estilos más complicados". Proyecto en el Archivo General de la
Administración, Alcalá de Henares, 04 078 26/15900

${ }^{37}$ En el proyecto de marzo de 1946, López-Izquierdo había proyectado una fachada principal más discreta, con un dístilo de un solo cuerpo sobre el que se disponía el balcón de autoridades y frontones curvos sobre los huecos de primera planta. La propuesta definitiva la firmó en de abril de 1950.

38 Jefatura del Estado. 1940. "Ley de 26 de enero de 1949 sobre Unidad Sindical". Boletín Oficial del Estado, January 31,1940: 772-773

${ }^{39}$ Rafael Aburto Renobales y Francisco de Asís Cabrero resultaron vencedores en 1949 en el "Concurso de anteproyectos para la construcción de la Casa Sindical en Madrid". 


\section{REFERENCIAS}

Adam, Peter. 1992. "Hitler y los arquitectos." In El arte del Tercer Reich, 206-227. Barcelona: Tusquets Editores.

Almuiña Diaz, Carlos and Xosé Lois Martínez Suárez. 1974 "Arquitectura." In Gran Enciclopedia Gallega, 89-91. Santiago: Silverio Cañada.

Almuiña Diaz, Carlos and Xosé Lois Martínez Suárez. 1975. "El período 1936-1950." In Rafael González Villar e a súa época. Vigo: C.O.A.G.

Bonet Correa, Antonio. 1981. "Espacios arquitectónicos para un nuevo orden." In Arte del franquismo, 11-46. Madrid: Cátedra.

Braunfels, Wolfgang. 1987. "Dominio político y arquitectura." In Urbanismo occidental, 1118. Madrid: Alianza Forma.

Capitel, Antón. 1995. "La arquitectura española del historicismo tardío en el período posterior a la Guerra Civil: 1939 - 1949." In Arquitectura española del siglo XX, 357-383. Madrid: Espasa Calpe.

Cirici Pellicer, Alexandre. 1977. La estética del franquismo. Barcelona: Gustavo Gili.

Diéguez Patao, Sofía. 1976. "Nueva política, nueva arquitectura." Arquitectura 199: 57-62.

Doménech Girbau, Lluís. 1978. Arquitectura de siempre. Los años 40 en España. Barcelona: Tusquets Editores.

Dóriga Tovar, César, 1967. "El cargo de Gobernador Civil y Jefe Provincial del Movimiento en el nuevo estado español." Revista de estudios políticos 156: 145-168.

Equipo redactor. 1942. "Plan Nacional de Gobiernos Civiles." Revista Nacional de Arquitectura 10-11: 31.

Equipo redactor. 1944. "Construcción del nuevo Gobierno Civil de Toledo en la Plaza de Zocodover." Reconstrucción 46: 277-286.

Equipo redactor. 1947a. "Mejoras de los edificios destinados a Gobiernos Civiles." Boletín de Información de la Dirección General de Arquitectura 3: 11-14.
Equipo Redactor. 1947b. "Noticias." Boletín de información de la Dirección General de Arquitectura 4: 35.

Fernández Fernández, Xosé. 1995. "Arquitectura institucional." In Arquitectura del Eclecticismo en Galicia, 29-174. A Coruña: Universidade Da Coruña.

Fernández Huidobro, Rafael. 1948. "Gobierno Civil." Revista Nacional de Arquitectura 75: 125-127.

Fisac Serna, Miguel. 1948. "Anteproyecto de Palacio Municipal y Gobierno Civil en Murcia." Revista Nacional de Arquitectura 75: 91-94.

García Viñolas, Manuel Augusto. 1943. "Sobre la creación de los estilos arquitectónicos." Revista Nacional de Arquitectura 18-19: 243.

Ibáñez Martín, José. "Discurso del Ministro de Educación Nacional." Revista Nacional de Arquitectura 38: 36-37.

Jefatura del Estado. 1940. "Ley de 26 de enero de 1949 sobre Unidad Sindical." Boletín Oficial del Estado, January 31,1940: 772-773.

Jefatura del Estado. 1997. "Ley 6/1997, de 14 de abril, de Organización y Funcionamiento de la Administración General del Estado: Artículo 29. Los Subdelegados del Gobierno." Boletín Oficial del Estado, April 15, 1997: 11762-11763.

Jefatura del Gobierno Nacional. 1939. "Ley de 23 de septiembre de 1939 creando la Dirección General de Arquitectura." Boletín Oficial del Estado, Septiembre 30, 1939: 5427.

Kruft, Hanno Walter. 1990. "Italia: futurismo y racionalismo." In Historia de la teoría de la arquitectura. Desde el siglo XIX hasta nuestros días, 687-704. Madrid: Alianza Editorial.

Llorente Hernández, Ángel. 1995. Arte e ideología en el franquismo (1936-1951). Madrid: Visor.

López Vázquez, José Manuel. 1981. "La arquitectura gallega contemporánea." In Galicia en el siglo XX, 1137-1153. Barcelona: Nauta.

Ministerio de Trabajo, Sanidad y Previsión. 1935, “Ley de la Previsión contra el Paro: Artículo 6. 
La arquitectura institucional política en Galicia durante la autarquía

Edificios Públicos." Gaceta de Madrid, June 26, 1935: 2443.

Palacios Ramilo, Antonio. 1945. "Ante una moderna arquitectura." Revista Nacional de Arquitectura 47-48: 405-413.

Reina de la Muela, Diego de. 1942. "Divagaciones arquitectónicas. Los imperios y su estilo." Reconstrucción 23: 193-194.

Seara Morales, lago. 1993. "De la arquitectura racionalista a la arquitectura de la Autarquía." In Arte contemporáneo, 328-351. A Coruña: Hércules de Ediciones.

Sobrino Manzanares, María Luisa. 1982. "El siglo XX: Arquitectura." In Historia del arte gallego, 423-436. Madrid: Alhambra.
Ureña Portero, Gabriel. 1979. Arquitectura y Urbanística Civil y Militar en el Período de la Autarquía (1936-1945), Madrid: Istmo.

Urrutia Núñez, Ángel. 1987. "La arquitectura de la Autarquía (1940-1950)." In Arquitectura del siglo XIX, del modernismo a 1936 y de 1940 a 1980. Zaragoza: Exclusivas de Ediciones

Vázquez Astorga, Mónica and Isabel A. Yeste Navarro. 2013. "El Gobierno Civil de Zaragoza y su sede institucional." Artigrama 26: 743-768.

Vigo Trasancos, Alfredo. 1990. "A arquitectura do século XX." In A arte galega. Estado da cuestión, 393-420. A Coruña: Publicacións do Consello da Cultura Galega. 